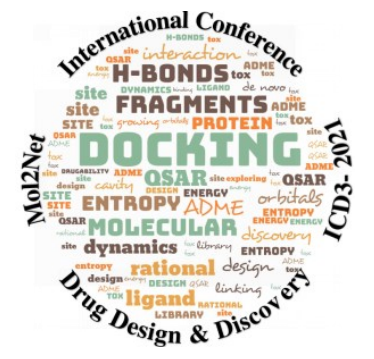

CHEMINFOICD3-03: Cheminfo. Int. Conf. Drug Des. \& Discov. Alfenas, Brazil-München,

Germany-Ch. Hill, Durham, USA, 2021

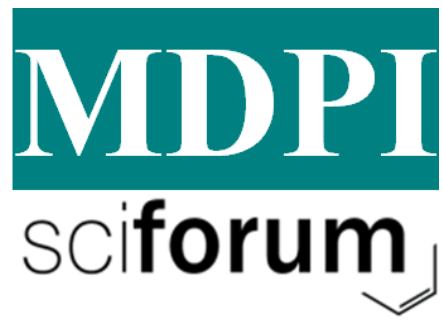

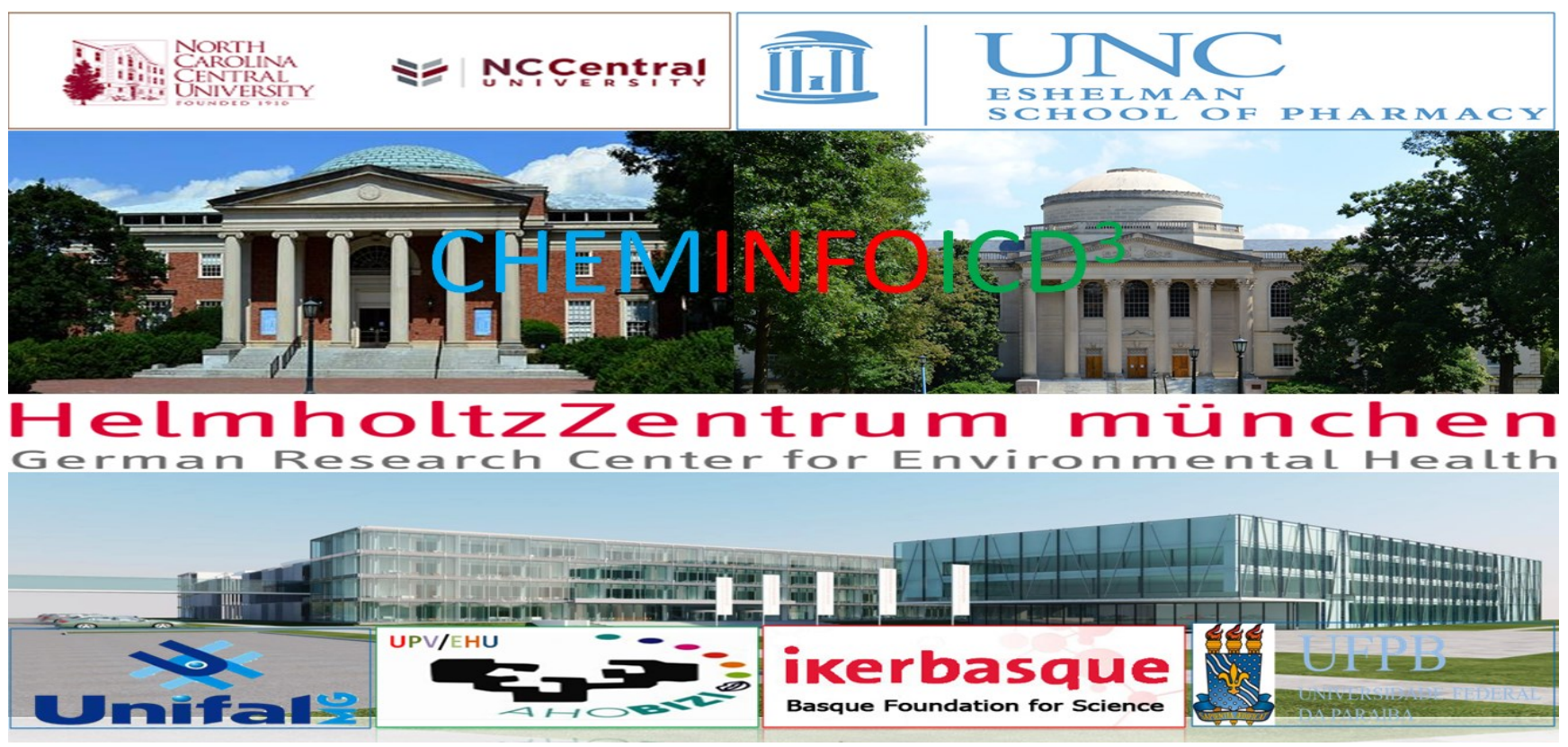

\title{
Predictive Modeling with Machine Learning and Perturbation Theory
}

\author{
Bernabe Ortega-Tenezaca ${ }^{a, b}$, Viviana F. Quevedo-Tumailli ${ }^{a, b}$ \\ ${ }^{a}$ RNASA-IMEDIR, Computer Science Faculty, University of A Coruña, 15071, A Coruña, Spain. \\ ${ }^{b}$ Universidad Estatal Amazónica UEA, Puyo, Pastaza, Ecuador.
}

\begin{abstract}
PTML is a combination of Machine Learning (ML) and Perturbation Theory (PT) that allows to create prediction models in many areas of knowledge mainly in Medicinal Chemistry to handle large amounts of data representing physical and chemical properties of different organisms and biological systems under different input conditions. PTML allows to establish dispersion measurements on descriptors of physicochemical properties of different organisms with high values of sensitivity, specificity and accuracy higher than $70 \%$.
\end{abstract}




\section{References}

1. Arrasate, S.; Duardo-Sanchez, A. Perturbation theory machine learning models: theory, regulatory issues, and applications to organic synthesis, medicinal chemistry, protein research, and technology. Curr. Top. Med. Chem., 2018, 18(14), 1203-1213. http://dx.doi.org/10.2174/1568026618666180810124031 PMID: 30095052

2. Ferreira da Costa, J.; Silva, D.; Caamaño, O.; Brea, J.M.; Loza, M.I.; Munteanu, C.R.; Pazos, A.; García-Mera, X.; González-Díaz, H. Perturbation Theory/Machine Learning Model of ChEMBL Data for Dopamine Targets: Docking, Synthesis, and Assay of New 1-Prolyl-1-leucyl-glycinamide Peptidomimetics. ACS Chem. Neurosci., 2018, 9(11), 2572-2587. http://dx.doi.org/10.1021/acschemneuro.8b00083 PMID: 29791132

3. Blazquez-Barbadillo, C.; Aranzamendi, E.; Coya, E.; Lete, E.; Sotomayor, N.; Gonzalez-Diaz, H. Perturbation theory model of reactivity and enantioselectivity of palladium-catalyzed Heck-Heck cascade reactions. RSC Advances, 2016, 6, 38602-38610. http://dx.doi.org/10.1039/C6RA08751E

4. Bernabe Ortega-Tenezaca, V.Q-T.; González-Díaz, H. In FRAMA 1.0: Framework for moving average operators' calculation in data analysis. Proceedings of MOL2NET, International Conference Series on Multidisciplinary Sciences; MDPI Sciforum, Basel, Switzerland 2017, p. 3.

5. Nocedo-Mena, D.; Cornelio, C.; Camacho-Corona, M.D.R.; Garza- González, E.; Waksman de Torres, N.; Arrasate, S.; Sotomayor, N.; Lete, E.; González-Díaz, H. Modeling antibacterial activity with machine learning and fusion of chemical structure information with microorganism metabolic networks. J. Chem. Inf. Model., 2019, 59(3), 1109-1120. http://dx.doi.org/10.1021/acs.jcim.9b00034 PMID: 30802402

6. Vásquez-Domínguez, E.; Armijos-Jaramillo, V.D.; Tejera, E.; González-Díaz, H. Multioutput perturbation-theory machine learning (ptml) model of chembl data for antiretroviral compounds. Mol. Pharm., 2019, 16(10), 4200-4212. http://dx.doi.org/10.1021/acs.molpharmaceut.9b00538 PMID: 31426639

7. Blay, V.; Yokoi, T.; González-Díaz, H. Perturbation theory- machine learning study of zeolite materials desilication. perturbation theory-machine learning study of zeolite materials desilication. J. Chem. Inf. Model., 2018, 58(12), 2414-2419. http://dx.doi.org/10.1021/acs.jcim.8b00383 PMID: 30139249 